\title{
BRAF mutations are associated with distinctive clinical, pathological and molecular features of colorectal cancer independently of microsatellite instability status \\ Wei Qi Li1 ${ }^{1}$ Kazuyuki Kawakami², Andrew Ruszkiewicz ${ }^{3}$, Graeme Bennett ${ }^{4}$, James Moore 5 and Barry Iacopetta*1
}

Address: ${ }^{1}$ School of Surgery and Pathology, University of Western Australia, Nedlands, WA 6009, Australia, ${ }^{2}$ Department of Surgery, Kanazawa University School of Medicine, Takaramachi 13-1, Kanazawa 920-8641, Japan, ${ }^{3}$ Division of Tissue Pathology, Institute of Medical and Veterinary Science, Frome Rd, Adelaide, SA 5000, Australia, ${ }^{4}$ Division of Molecular Pathology, Institute of Medical and Veterinary Science, Frome Rd, Adelaide, SA 5000, Australia and ${ }^{5}$ Colorectal Surgery Unit, Royal Adelaide Hospital, Adelaide, SA 5000, Australia

Email: Wei Qi Li - liw04@student.uwa.edu.au; Kazuyuki Kawakami - kawakami@med.m.kanazawa-u.ac.jp; Andrew Ruszkiewicz - andrew.ruszkiewicz@imvs.sa.gov.au; Graeme Bennett - graeme.bennett@imvs.sa.gov.au; James Moore - james.moore@adelaide.edu.au; Barry Iacopetta* - bjiac@cyllene.uwa.edu.au

* Corresponding author

Published: 10 January 2006

Molecular Cancer 2006, 5:2 doi:10.1186/1476-4598-5-2
Received: 18 August 2005

Accepted: 10 January 2006

This article is available from: http://www.molecular-cancer.com/content/5/I/2

(C) 2006 Qi Li et al; licensee BioMed Central Ltd.

This is an Open Access article distributed under the terms of the Creative Commons Attribution License (http://creativecommons.org/licenses/by/2.0), which permits unrestricted use, distribution, and reproduction in any medium, provided the original work is properly cited.

\begin{abstract}
Background: BRAF is a member of RAF family of serine/threonine kinases and mediates cellular responses to growth signals through the RAS-RAF-MAP kinase pathway. Activating mutations in $B R A F$ have recently been found in about $10 \%$ of colorectal cancers, with the vast majority being a V600E hotspot mutation. The aim of the present study was to evaluate the clinical, pathological and molecular phenotype of colorectal tumors with BRAF mutations.
\end{abstract}

Results: Mutations in BRAF were identified in $8 \%$ (23/275) of colorectal cancers. They were 5-10fold more frequent in tumors with infiltrating lymphocytes, location in the proximal colon, poor histological grade and mucinous appearance $(P<0.002$ for each). Tumors with BRAF mutation were also 10 -fold more likely to show microsatellite instability and frequent DNA methylation $(P<$ $0.000 \mathrm{I})$ compared to tumors without this mutation. The characteristic morphological features of tumors with BRAF mutation (infiltrating lymphocytes, poor grade, mucinous) remained after stratification according to microsatellite instability and methylator phenotypes. Mutations in BRAF were mutually exclusive with mutations in KRAS but showed no clear association with the presence of TP53 mutation.

Conclusion: BRAF mutation identifies a colorectal cancer subgroup with distinctive phenotypic properties independent of microsatellite instability status and thus could be a valuable marker for studies into the clinical properties of these tumors.

\section{Background}

$B R A F$ is a member of the RAF family of kinases that acts upstream of the MEK1/2 kinases in response to RAS sig- nals. Activating mutations in BRAF have been reported in $5-15 \%$ of colorectal carcinomas (CRC), with by far the most common mutation being a 1796T to A transversion 
(A) BRAF V600E mutation screening using F-SSCP

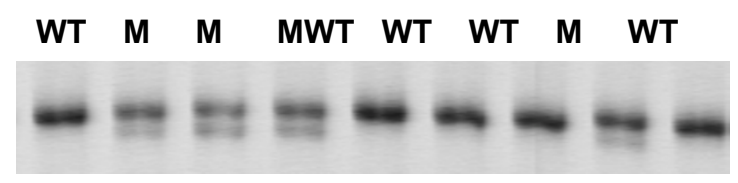

(B)DNA sequence showing BRAF 1799T to A mutation

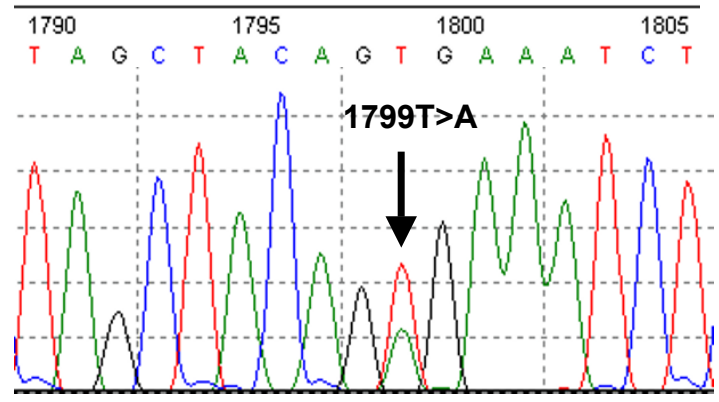

Figure I

(A) Representative F-SSCP gel used to detect BRAF mutationsin colorectal cancer. WT, wild-type; $M$, mutation. (B) DNA sequencing gel resultconfirms the presence of a I799T to $A$ mutation giving rise to the $\mathrm{V} 600 \mathrm{E}$ mutation.

leading to a V600E substitution [1-3]. The BRAF V600E hotspot mutation is strongly associated with the microsatellite instability (MSI+) phenotype but is mutually exclusive with KRAS mutations [4-7]. Interestingly, BRAF mutations are found only in MSI+ sporadic tumors that result from aberrant $M L H 1$ promoter methylation and do not occur in MSI+ tumors from hereditary non-polyposis colorectal cancer (HNPCC) patients [5,8-10], thus providing a convenient discriminator between sporadic and familial cases. The majority of $\mathrm{MSI}+$ sporadic tumors belong to a larger CRC group referred to as the $\mathrm{CpG}$ island methylator phenotype (CIMP+) that is characterised by widespread hypermethylation of $\mathrm{CpG}$ islands located with gene promoter regions [11]. Both MSI+ and CIMP+ tumors are thought to arise from large hyperplastic polyps and serrated adenomas $[12,13]$ and recent work has demonstrated a high frequency of BRAF mutations in these lesions $[7,14,15]$.

Although the positive association with MSI+ and inverse association with KRAS mutation have been well documented, little is known about the other properties of tumors with BRAF mutation. In the present study we analysed for BRAF V600E mutations in a consecutive series of 275 CRCs that were well characterised for the major pathological and molecular features of this disease. Our results demonstrate that oncogenic BRAF mutation occurs prefer- entially within a subgroup of CRCs that have distinctive features. It could therefore be used as a convenient marker for the further characterisation of these tumors, particularly in relation to their prognosis and response to adjuvant chemotherapy.

\section{Results}

Figure 1A shows representative Fluorescent-SSCP results for the screening of BRAF mutations in this CRC series, while Figure $1 \mathrm{~B}$ shows DNA sequencing confirmation of the $1799 \mathrm{~T}$ to A transversion resulting in the V600E mutation. The overall frequency of BRAF mutation was $8.4 \%$ $(23 / 275)$, comparing favourably with frequencies of 9$11 \%$ reported for other large studies of this tumor type $[6,16,17]$. The mean age of patients with and without $B R A F$ mutation was identical (Table 1). Strong associations were observed between $B R A F$ mutation and tumor origin in the proximal side of the large bowel, poor histological grade, mucinous appearance and the presence of infiltrating lymphocytes. Higher frequencies of $B R A F$ mutation were also observed in females and in node negative tumors but these did not reach significance.

BRAF mutations showed no association with TP53 mutations and were mutually exclusive with the presence of KRAS mutations (Table 2). In contrast, BRAF mutations were approximately 10 -fold more frequent in $\mathrm{MSI}+$ and $\mathrm{CIMP}+$ tumors compared to tumors without these phenotypes. A strong association was also seen with methylation of the MLH1 gene promoter and in particular with methylation of its proximal region. We have previously examined the methylation status of 7 different $\mathrm{CpG}$ islands in this CRC series [18]. The mean number of these methylated sites was 3-fold higher in tumors with BRAF mutation compared to those without $(2.6 \pm 1.7$ vs $0.8 \pm 1.0 ; P$ $<0.001)$. Multivariate analysis revealed that MSI+ was the only significant independent predictor of BRAF mutation $(\mathrm{RR}=6.3,95 \% \mathrm{CI}[1.2-32.3] ; P=0.028)$ in a model that included CIMP+, tumor site, histological grade, presence of infiltrating lymphocytes and mucinous appearance.

We next examined whether the characteristic features of tumors with BRAF mutation were still apparent following stratification into MSI and CIMP phenotypes. Although the statistical power of this subgroup analysis was limited, the morphological features of infiltrating lymphocytes, poor histological grade and mucinous appearance were clearly associated with $B R A F$ mutation regardless of tumor MSI status (Table 3). Similarly, these features were each more common in tumors with BRAF mutation in both the CIMP- and CIMP+ subgroups (Table 4). Similar to previous observations in a separate CRC cohort [20], the frequency of KRAS mutation was lower in MSI+ compared to MSI- tumors $(P=0.034$; Table 3$)$, while the frequency of TP53 mutation was also considerably lower in MSI+ 
Table I: Associations between BRAF mutation and clinicopathological features of colorectal cancer.

\begin{tabular}{|c|c|c|c|}
\hline Feature (n) ${ }^{a}$ & BRAF wild-type (\%) & BRAF mutation (\%) & $P$ \\
\hline Total (275) & $252(92)$ & $23(8)$ & \\
\hline Age (yrs) & $68.4 \pm 13.0$ & $68.4 \pm 20.7$ & NS \\
\hline \multicolumn{4}{|l|}{ Gender } \\
\hline Men (I32) & $124(94)$ & $8(6)$ & \\
\hline Women $(100)$ & $87(87)$ & $13(13)$ & 0.068 \\
\hline \multicolumn{4}{|l|}{ Infiltrating lymphocytes } \\
\hline Negative (199) & $190(95)$ & $9(5)$ & \\
\hline Positive (2I) & II (52) & $10(48)$ & $<0.0001$ \\
\hline \multicolumn{4}{|l|}{ Nodal involvement } \\
\hline Negative (128) & $115(90)$ & $13(10)$ & \\
\hline Positive (70) & $66(94)$ & $4(6)$ & NS \\
\hline \multicolumn{4}{|l|}{ Tumor site } \\
\hline Proximal (93) & $79(85)$ & $14(15)$ & \\
\hline Distal (126) & $122(97)$ & $4(3)$ & 0.0015 \\
\hline \multicolumn{4}{|l|}{ Histological grade } \\
\hline Well/moderate (140) & $133(95)$ & $7(5)$ & \\
\hline Poor (29) & $22(76)$ & $7(24)$ & 0.0006 \\
\hline \multicolumn{4}{|l|}{ Mucinous } \\
\hline Negative (159) & $150(94)$ & $9(6)$ & \\
\hline Positive (27) & $20(74)$ & $7(26)$ & 0.0005 \\
\hline
\end{tabular}

a Data was unavailable for gender in 43 cases, infiltrating lymphocytes in 55 cases, nodal involvement in 77 cases, tumor site in 56 cases, grade in 106 cases and mucinous appearance in 89 cases.

tumors with wildtype BRAF than in MSI- tumors with wildtype BRAF $(P=0.014)$.

\section{Discussion}

The BRAF V600E mutation has already been proposed as a convenient marker to discriminate between MSI+ tumors that are sporadic or HNPCC in origin [5,8-10]. This is a very important issue for population-based screening programs that aim to identify CRC associated with the HNPCC syndrome. Compared to the analysis of MLH1 promoter methylation, mutation at the BRAF V600E hotspot is relatively simple to detect using DNA sequencing, RFLP or the SSCP method used in the present work (Figure 1).

Similar to other studies $[4,5,10,16,17]$ we observed $B R A F$ mutation frequencies of $4 \%$ in MSI- tumors and 39\% in MSI+ tumors (Table 1). The highest frequencies were seen in tumors showing methylation of the MLH1 promoter proximal region $(46 \%)$ and in tumors with infiltrating lymphocytes $(48 \%)$. BRAF mutation frequencies of up to $70-80 \%$ have been reported in sporadic MSI+, CIMP+ and MLH1-methylated CRC and polyps $[7,8,15,16]$. For reasons that are still unclear, $B R A F$ mutations are approximately 5-10-fold more frequent in tumors that have characteristic features of sporadic MSI+ (ie. MLH1 methylated) and CIMP+ phenotypes. These include proximal colon location, poor differentiation, mucinous histology and infiltrating lymphocytes $[13,19,20]$. Interestingly however, in the present study BRAF mutations never occurred in association with KRAS mutation, were present in only $3 \%$ of CIMP- tumors and showed no association with TP53 mutation (Table 2). The observation that BRAF mutations occur only very rarely in HNPCC-related MSI+ CRC demonstrates that defective DNA mismatch repair is not involved in causing this genetic alteration.

In order to determine whether the characteristic clinicopathological features of tumors with $B R A F$ mutation were due to their close association with MSI+ and CIMP+, we stratified tumours according to these phenotypes. Despite having only $9 \mathrm{MSI}-/ B R A F$ mutant and 5 CIMP-/BRAF mutant tumors, the results showed that associations between BRAF mutation and the morphological properties of tumor-infiltrating infiltrating lymphocytes, poor histological grade and mucinous phenotype were retained (Tables 3 and 4).

The frequencies of BRAF mutation observed in MSI- (4\%) and MSI+ (39\%) tumors in the present study compare 
Table 2: Associations between BRAF mutation and molecular features of colorectal cancer.

\begin{tabular}{|c|c|c|c|}
\hline Feature (n) ${ }^{a}$ & BRAF wild-type (\%) & BRAF mutation (\%) & $P$ \\
\hline Total (275) & $252(92)$ & $23(8)$ & \\
\hline \multicolumn{4}{|l|}{ MSI } \\
\hline negative (204) & $195(96)$ & $9(4)$ & \\
\hline positive (3I) & $19(6 \mathrm{I})$ & $12(39)$ & $<0.0001$ \\
\hline \multicolumn{4}{|l|}{ Methylation status } \\
\hline CIMP- (I50) & 145 (97) & $5(3)$ & \\
\hline $\mathrm{CIMP}+(42)$ & $31(74)$ & $11(26)$ & $<0.0001$ \\
\hline \multicolumn{4}{|l|}{ MLHI distal region } \\
\hline Negative (168) & $159(95)$ & $9(5)$ & \\
\hline Positive (24) & $17(7 \mid)$ & $7(29)$ & $<0.0001$ \\
\hline \multicolumn{4}{|c|}{ MLHI proximal region } \\
\hline Negative (179) & $169(94)$ & $10(6)$ & \\
\hline Positive (13) & $7(54)$ & $6(46)$ & $<0.0001$ \\
\hline \multicolumn{4}{|l|}{ KRAS } \\
\hline Wild-type (I56) & $134(86)$ & $22(14)$ & \\
\hline Mutant (93) & $93(100)$ & $0(0)$ & $<0.0001$ \\
\hline \multicolumn{4}{|l|}{ TP53 } \\
\hline Wild-type (183) & $166(91)$ & $17(9)$ & \\
\hline Mutant (66) & $62(94)$ & $4(6)$ & NS \\
\hline
\end{tabular}

a Data was unavailable for MSI status in 40 cases, methylation status in 83 cases, KRAS mutation in 26 cases and TP53 mutation in 26 cases

favourably ( $5 \%$ and $52 \%$, respectively) to those reported recently in another large, population-based study [17]. Although BRAF mutations are much more frequent in MSI+ tumors, the comparative rarity of this phenotype means that a considerable proportion occur in MSItumors. In the present study, $43 \%$ of all BRAF mutations occurred in MSI- tumors compared to $48 \%$ in the study by
Samowitz et al [17]. BRAF mutations were reported to show prognostic significance in MSI- but not in MSI+ CRC [17]. The lack of follow-up information on CRC patients in the current study and the small number of BRAF mutations $(\mathrm{n}=21)$ meant that we were unable to evaluate the prognostic significance of BRAF mutation according to MSI status.

Table 3: Clinicopathological and molecular features of BRAF mutant colorectal cancers stratified according to microsatellite instability status.

\begin{tabular}{|c|c|c|c|c|c|c|}
\hline \multirow[b]{2}{*}{ Feature } & \multicolumn{2}{|c|}{ MSI- } & \multirow[b]{2}{*}{$\mathbf{P}$} & \multicolumn{2}{|c|}{ MSI+ } & \multirow[b]{2}{*}{$P$} \\
\hline & $\begin{array}{c}\text { BRAF WT } \\
(\mathrm{n}=192)(\%)\end{array}$ & $\begin{array}{c}\text { BRAF M } \\
(\mathrm{n}=9)(\%)\end{array}$ & & $\begin{array}{l}\text { BRAF WT } \\
(\mathrm{n}=19)(\%)\end{array}$ & $\begin{array}{c}\text { BRAF M } \\
(n=12)(\%)\end{array}$ & \\
\hline Age (years) & $68.5 \pm 12.6$ & $58.2 \pm 26.5$ & NS & $67.5 \pm 16.8$ & $76.1 \pm 10.9$ & NS \\
\hline Females & 39 & 44 & NS & 63 & 75 & NS \\
\hline TILS + a & 3 & 44 & 0.0004 & 28 & 60 & 0.08 \\
\hline Node negative & 62 & 62 & NS & 81 & 89 & NS \\
\hline Proximal site & 36 & 67 & 0.05 & 72 & 89 & NS \\
\hline Poor grade & 15 & 40 & 0.12 & 25 & 56 & 0.11 \\
\hline Mucinous & 12 & 53 & 0.05 & 6 & 44 & 0.04 \\
\hline CIMP+ & 15 & 50 & 0.03 & 40 & 88 & 0.03 \\
\hline Dist. MLHI methylated & 7 & 12 & NS & 40 & 75 & 0.10 \\
\hline Prox. MLHI methylated & 1 & 0 & NS & 33 & 75 & 0.06 \\
\hline KRAS mutant & 43 & 0 & 0.008 & 21 & 0 & 0.12 \\
\hline TP53 mutant & 29 & 11 & NS & 5 & 18 & NS \\
\hline
\end{tabular}

aTumor-infiltrating lymphocytes 
Table 4: Clinicopathological and molecular features of BRAF mutant colorectal cancers stratified according to methylator phenotype status.

\begin{tabular}{|c|c|c|c|c|c|c|}
\hline \multirow[b]{2}{*}{ Feature } & \multicolumn{2}{|c|}{ CIMP. } & \multirow[b]{2}{*}{$P$} & \multicolumn{2}{|c|}{ CIMP+ } & \multirow[b]{2}{*}{$P$} \\
\hline & $\begin{array}{c}\text { BRAF WT } \\
(\mathrm{n}=145)(\%)\end{array}$ & $\begin{array}{l}\text { BRAF M } \\
(\mathrm{n}=5)(\%)\end{array}$ & & $\begin{array}{l}\text { BRAF WT } \\
(\mathrm{n}=31)(\%)\end{array}$ & $\begin{array}{c}\text { BRAF M } \\
(n=11)(\%)\end{array}$ & \\
\hline Age (years) & $68.3 \pm 13.5$ & $71.0 \pm 11.0$ & NS & $71.7 \pm 11.8$ & $65.4 \pm 26.3$ & NS \\
\hline Females & 37 & 60 & NS & 42 & 45 & NS \\
\hline TILS + & 2 & 40 & 0.008 & 17 & 45 & 0.06 \\
\hline Node negative & 63 & 60 & NS & 65 & 82 & NS \\
\hline Proximal site & 35 & 60 & NS & 74 & 80 & NS \\
\hline Poor grade & 13 & 66 & 0.05 & 20 & 40 & NS \\
\hline Mucinous & 9 & 25 & NS & 25 & 45 & NS \\
\hline MSI+ & 6 & 20 & NS & 19 & 64 & 0.01 \\
\hline Dist. MLHI methylated & 3 & 0 & NS & 42 & 64 & NS \\
\hline Prox. MLHI methylated & 0 & 0 & NS & 23 & 55 & 0.05 \\
\hline KRAS mutant & 43 & 0 & 0.06 & 55 & 0 & 0.001 \\
\hline TP53 mutant & 26 & 0 & NS & 29 & 20 & NS \\
\hline
\end{tabular}

\section{Conclusion}

Findings from the present study and from previous work indicate that BRAF mutation is likely to be a convenient marker for the identification of a subset of CRCs with distinctive clinical, pathological and molecular features and which may originate in hyperplastic polyps and serrated adenomas $[7,14,15]$. In view of the strong associations between BRAF mutation and specific pathological (site, grade, mucinous, infiltrating lymphocytes) and molecular (methylated MSI+, CIMP+, wildtype KRAS) features, it will be interesting in future studies to determine the predictive significance of this marker for response to adjuvant therapies in CRC.

\section{Methods}

The 275 colorectal tumors investigated in this study were obtained from the Colorectal Unit of the Royal Adelaide Hospital. These were snap frozen in liquid nitrogen within $20-40 \mathrm{~min}$ after resection and stored at $-70^{\circ} \mathrm{C}$ prior to extraction of DNA. Clinical data available for this series included patient age, sex and family history of CRC. Only one case was confirmed as HNPCC-related. Pathological data included nodal involvement, tumor site, histological grade, mucinous appearance and the presence of infiltrating lymphocytes. Evaluation of MSI+ [21], CIMP+ [18], KRAS mutation [22] and TP53 mutation [23] were performed as described previously by our group. Mutations in exon 15 of BRAF including the V600E hotspot were detected using the PCR primer sequences reported earlier [1], the F-SSCP method [22,23] and confirmed by direct sequencing.

Statistical analyses were performed using SPSS Version 12.0 (Chicago, Illinois, USA). Associations between BRAF mutation and clinical, pathological or molecular features were evaluated using Fisher's exact or Pearson's chi- squared tests as appropriate. Multivariate analysis was performed using binary logistic regression with $B R A F$ mutation as the dependent variable.

\section{List of abbreviations}

Colorectal carcinoma, CRC; microsatellite instability, $\mathrm{MSI}+$; hereditary non-polyposis colorectal cancer, HNPCC; CpG island methylator phenotype, CIMP+; fluorescent single strand conformation polymorphism, FSSCP; tumor-infiltrating lymphocytes, TILs.

\section{Authors' contributions}

WL analysed for BRAF mutations using SSCP. KK carried out the methylation analyses. AR characterized the tumor series for pathological features. GB carried out the analysis for MSI+ status and DNA sequencing of BRAF. JM was largely responsible for establishment of the tumor bank. WL, KK, AR and BI analysed and interpreted the data and BI prepared the manuscript. All authors read and approved the final version of the manuscript.

\section{Acknowledgements}

The authors are grateful to Fabienne Grieu for assistance with optimization of the BRAF mutation screening procedure and to Cassandra Clayforth for advice with statistical analysis. This work was supported by NHMRC grant 353552 to B lacopetta.

\section{References}

I. Davies H, Bignell GR, Cox C, Stephens P, Edkins S, Clegg S, Teague J, Woffendin H, Garnett MJ, Bottomley W, Davis N, Dicks E, Ewing R, Floyd Y, Gray K, Hall S, Hawes R, Hughes J, Kosmidou V, Menzies A, Mould C, Parker A, Stevens C, Watt S, Hooper S, Wilson R, Jayatilake H, Gusterson BA, Cooper C, Shipley J, Hargrave D, Pritchard-Jones K, Maitland N, Chenevix-Trench G, Riggins GJ, Bigner DD, Palmieri G, Cossu A, Flanagan A, Nicholson A, Ho JW, Leung SY, Yuen ST, Weber BL, Seigler HF, Darrow TL, Paterson H, Marais R, Marshall C] Wooster R, Stratton MR, Futreal PA: Mutations of the BRAF gene in human cancer. Nature 2002, 417:949-954. 
2. Rajagopalan H, Bardelli A, Lengauer C, Kinzler KW, Vogelstein B, Velculescu VE: Tumorigenesis: RAF/RAS oncogenes and mismatch-repair status. Nature 2002, 4I8:934.

3. Yuen ST, Davies H, Chan TL, Ho JW, Bignell GR, Cox C, Stephens P, Edkins S, Tsui WW, Chan AS, Futreal PA, Stratton MR, Wooster R, Leung SY: Similarity of the phenotypic patterns associated with BRAF and KRAS mutations in colorectal neoplasia. Cancer Res 2002, 62:645I-6455.

4. Oliveira C, Pinto M, Duval A, Brennetot C, Domingo E, Espin E, Armengol M, Yamamoto H, Hamelin R, Seruca R, Schwartz S Jr: BRAF mutations characterize colon but not gastric cancer with mismatch repair deficiency. Oncogene 2003, 22:9192-9196.

5. Deng G, Bell I, Crawley S, Gum J, Terdiman J, Allen B, Truta B, Sleisenger M, Kim Y: BRAF mutation is frequently present in sporadic colorectal cancer with methylated hMLHI, but not hereditary nonpolyposis colorectal cancer. Clin Cancer Res 2004, 10:191-195.

6. Nagasaka T, Sasamoto H, Notohara K, Cullings HM, Takeda M, Kimura K, Kambara T, MacPhee DG, Young J, Leggett BA, Jass JR, Tanaka N, Matsubara N: Colorectal cancer with mutation in $B R A F, K R A S$, and wild-type withrespect to both oncogenes showing different patterns of DNA methylation. J Clin Oncol 2004, 22:4584-4594.

7. Yang S, Farraye FA, Mack C, Posnik O, O'Brien MJ: BRAF and KRAS Mutations in hyperplastic polyps and serrated adenomas of the colorectum: relationship to histology and CpG island methylation status. Am J Surg Pathol 2004, 28: I 452-1459.

8. McGivern A, Wynter CV, Whitehall VL, Kambara T, Spring KJ, Walsh MD, Barker MA, Arnold S, Simms LA, Leggett BA, Young J, Jass JR: Promoter hypermethylation frequency and BRAF mutations distinguish hereditary non-polyposis colon cancer from sporadic MSI-H colon cancer. Fam Cancer 2004, 3: I0I- 107.

9. Miyaki M, lijima T, Yamaguchi T, Kadofuku T, Funata N, Mori T: Both $B R A F$ and KRAS mutations are rare in colorectal carcinomas from patients with hereditary nonpolyposis colorectal cancer. Cancer Lett 2004, 2 I I:105-109.

10. Domingo E, Laiho P, Ollikainen M, Pinto M, Wang L, French AJ, Westra J, Frebourg T, Espin E, Armengol M, Hamelin R, Yamamoto $H$, Hofstra RM, Seruca R, Lindblom A, Peltomaki P, Thibodeau SN, Aaltonen LA, Schwartz S: BRAF screening as a low-cost effective strategy for simplifying HNPCC genetic testing. J Med Genet 2004, 41:664-668.

II. Toyota M, Ahuja N, Ohe-Toyota M, Herman JG, Baylin SB, Issa JP: CpG island methylator phenotype in colorectal cancer. Proc Natl Acad Sci USA 1999, 96:868I-8686.

12. Hawkins NJ, Ward RL: Sporadic colorectal cancers with microsatellite instability and their possible origin in hyperplastic polyps and serrated adenomas. I Natl Cancer Inst 200I, 93:1307-1313.

13. Jass JR, Whitehall VL, Young J, Leggett BA: Emerging concepts in colorectal neoplasia. Gastroenterology 2002, I 23:862-876.

14. Chan TL, Zhao W, Leung SY, Yuen ST, Cancer Genome Project: BRAF and KRAS mutations in colorectal hyperplastic polyps and serrated adenomas. Cancer Res 2003, 63:4878-488I.

15. Kambara T, Simms LA, Whitehall VL, Spring KJ, Wynter CV, Walsh MD, Barker MA, Arnold S, McGivern A, Matsubara N, Tanaka N Higuchi T, Young J, Jass JR, Leggett BA: BRAF mutation is associated with DNA methylation in serrated polyps and cancers of the colorectum. Gut 2004, 53: I I37-I I 44.

16. Koinuma K, Shitoh K, Miyakura Y, Furukawa T, Yamashita Y, Ota J, Ohki R, Choi YL, Wada T, Konishi F, Nagai H, Mano H: Mutations of BRAF are associated with extensive $h M L H I$ promoter methylationin sporadic colorectal carcinomas. Int J Cancer 2004, 108:237-242.

17. Samowitz WS, Sweeney C, Herrick J, Albertsen H, Levin TR, Murtaugh MA, Wolff RK, Slattery ML: Poor survival associated with the BRAF V600E mutation in microsatellite-stable colon cancers. Cancer Res 2005, 65:6063-6069.

18. Kawakami K, Ruszkiewicz A, Bennett G, Moore J, Watanabe G, lacopetta $B$ : The folate pool in colorectal cancers is associated with DNA hypermethylation and with a polymorphism in methylenetetrahydrofolate reductase. Clin Cancer Res 2003, 9:5860-5865.

19. Hawkins N, Norrie M, Cheong K, Mokany E, Ku SL, Meagher A, O'Connor T, Ward R: CpG island methylation in sporadic colorectal cancers and its relationship to microsatellite instability. Gastroenterology 2002, I 22:1376-1387.

20. van Rijnsoever M, Grieu F, Elsaleh H, Joseph D, lacopetta B: Characterisation of colorectal cancers showing hypermethylation at multiple CpG islands. Gut 2002, 5 I:97-802.

2I. Ruszkiewicz A, Bennett G, Moore J, Manavis J, Rudzki B, Shen L, Suthers G: Correlation of mismatch repair genes immunohistochemistry and microsatellite instability status in HNPCCassociated tumors. Pathology 2002, 34:54I-547.

22. Wang C, van Rijnsoever M, Grieu F, Bydder S, Elsaleh H, Joseph D, Harvey J, lacopetta B: Prognostic significance of microsatellite instability and Ki-ras mutation type in stage II colorectal cancer. Oncology 2003, 64:259-265.

23. lacopetta B, Elsaleh H, Grieu F, Joseph D, Sterrett G, Robbins P: Routine analysis of p53 mutation in clinical breast tumor specimens using fluorescence-based polymerase chain reaction and single strand conformation polymorphism. Diagn Mol Pathol 2000, 9:20-25.
Publish with Biomed Central and every scientist can read your work free of charge

"BioMed Central will be the most significant development for disseminating the results of biomedical research in our lifetime. "

Sir Paul Nurse, Cancer Research UK

Your research papers will be:

- available free of charge to the entire biomedical community

- peer reviewed and published immediately upon acceptance

- cited in PubMed and archived on PubMed Central

- yours - you keep the copyright
BioMedcentral 